\title{
THE EMPIRICAL REVIEW OF THE ORGANIZATIONAL, TECHNOLOGICAL, ENVIRONMENTAL AND HUMAN RESOURCES FACTORS ON THE EFFICIENCY OF THE DIGITAL TRANSFORMATION, OMAN
}

\author{
Nassr Khalfan Salim Al Maamari \\ Faculty of Business and Accountancy (FBA) \\ University Selangor (Unisel), Shah Alam, Malaysia \\ E-mail: nksmamari@gmail.comis \\ Abul Bashar Bhuiyan \\ Faculty of Business and Accountancy (FBA) \\ University Selangor (Unisel), Shah Alam, Malaysia \\ E-mail: bashariuk@gmail.com
}

\begin{abstract}
The Sultanate of Oman accepts and uses e-services among public services, which largely depend on the institutional process and implementation of e-government, sometimes with different preferences for the reality of digitalization. It is important and plays an important role in the economic, political and prosperity of the Middle East. Therefore, the country is focusing on technology that enables services and government-wide strategies. Regarding such issues, the main aim of the study is to examine the means available to examine the effectiveness of electronic services and digital transformation in the selected public sector in the Sultanate of Oman. The study used online empirical sources in the names of organizational, technology, environment and human resource factors, as well as the effectiveness of digital change in various online database sources such as Google Scholars, Springer Link, Wiley, Science Direct, JSTOR, Emerald Full text, Scopus and EBSCO HOST, etc. The review results show that organizational, technological, environmental and human factors play an important role in ensuring the effectiveness of the public sector in the digital transformation in the Sultanate of Oman. The study also found that the success of e-government in Oman depends on the willingness and intention of citizens to use e-government services. The country's government should consider developing vital IT projects, ignoring citizens' opinions, to make traditional services more efficient online. Understanding citizen adoption is an important element of EGovernment, enabling it to provide policymakers and decision makers with a range of strategic management plans and actions to build and rapidly accelerate adoption of these services to increase citizen participation, also the adoption rate. A summary of the study's findings provides guidance for the future scope of empirical research to ensure the effectiveness of the public sector for digital transformation in the Sultanate of Oman and its regions.
\end{abstract}

Keywords: E-Government, E-Services, Digital Transformation \& Oman. 


\section{INTRODUCTION}

The e-Government (Electronic Government or Electronic Governance) has developed tremendously in the late 1990's as a framework within which to provide know-hows among practitioners in the implementation of e-Gov. Over the past decades e-Government provided abrupt increase to numerous conferences with more and more advance scientific content (AlMaimani \& Johari, 2014) . Moreover, the new information technology ( IT ) in its application has become very popular and widely used system in the recent years and in particular combined, organization-wide information systems is an increasingly common form of change in large firms. The best example system of such application is Enterprise Resource Planning (ERP) (Rossouw \& Alexander, 2015). Another study argued that E-Government realization becomes urgent essential with prompt technological developments and increasing struggle of daily life, most especially in developing countries. Governments in these countries (developing countries) are responsible for accomplishing their promises to attain the advantages of electronic transformation intended for public and /or society use (Alrawabdeh, 2014).

There is public sectors transformation have initiated a drive in the Gulf Region with many countries considerably making investment into electronic government initiatives; one to mention is the Sultanate of Oman is among those countries which prominently consider the technology to be adopted. However accordingly, to current date only minimal development has been made in terms of realizing fully a functional and integrated e-government services in the Sultanate. The proliferation of digital technology and important improvements in information and communication technologies (ICT's) tremendously change the way most governments in the Gulf Cooperation Council (GCC) region interact and work together with citizens, deliver their services and how they participate with other governments in the region (Al-Busaidy \& Weerakkody, 2011). (Marchio, Benedetti, \& Russo, 2015), comments on the method used to identify some relevant implications in the adoption of e-government service. Accordingly, different countries adopt a distinct service that maybe useful for them according to their needs for development. However, in order to determine and classify various guidelines and procedures to each specific country, a two - step methodology is adopted to allow and can propose and recommend to achieve aims by policy makers of the state.(Cummings \& Feyerherm, 2016), states that the system aspects and components can be affected by any transformation because it involves large systems. For organizational development experts, it is of great consideration to examine and identify what involvement is most suitable and applicable for a specific large system to be adopted ( $\mathrm{Li}, \mathrm{Su}, \mathrm{Zhang}, \&$ Mao, 2018).

Hence, in spite of the available technology that are currently in use, still there are numerous barriers facing E-Service Technology mostly in Developing Countries as it has been shown in various survey results. Analysis obtained shows high scores on the following areas such as; Political crisis, Trust issue whereby users are not confident, Finance issue on investment as to its transparency, Usability Issues, Leadership and Management - which are prone to Corruption, Cultural differences that leads to a clash on the available e-service. Moreover, the lack of information security and privacy as such users both public and private remain unsure of the confidential information supplied to the system, Resistance to E-Platform change and lack of E-Government service knowledge where most users specially the non - educated which are left behind as to knowhow and the lack of knowledge on how to use the modern technology adopted by the government (Al Salmi, Mohtar, \& Hasnan, 2017). The e-government success in Oman is dependent upon its citizen readiness and intention to use e-government services. Government of the country should give vital consideration to develop IT projects without overlooking to 
consider the citizen's viewpoints in order to have better transition of traditional services to online form effectively (Al-Busaidy \& Weerakkody, 2011). An understanding of the citizen approval are significant factors in e-government, whereby it can provide policy and decision makers with a set of strategic management plans and actions in order to form and quick pace of greater acceptance towards these services in increasing the citizens' adoption rate as well. In Such circumstances, the Sultanate of Oman accepts and uses e-services among public services, which largely depend on the institutional process and implementation of e-government, sometimes with different preferences for the reality of digitalization. It is important and plays an important role in the economic, political and prosperity of the Middle East. Therefore, the country is focusing on technology that enables services and government-wide strategies. Regarding such issues, the main aim of the study is to examine the means available to examine the effectiveness of electronic services and digital transformation in the selected public sector in the Sultanate of Oman.

\section{Digital Transformation}

\section{BACKGROUND OF THE STUDY}

In the past decades, digital developments have radically transformed the world. New technologies and resulting organizational structures have come to form an integral part of modern life. While the Digital Transformation has led to an incredible number of business opportunities, it has completely changed risks people and companies are exposed to. This is not a static change, as technological and organizational trends continuously change the way people work and share information. Digital Trust \& Security development must keep up with these trends to stay ahead of implied threats. Social Media. Both in private settings as well as in the work sphere, social media provide convenient means of communication and collaboration (Filgueiras, Flávio, \& Palotti, 2019). The (Internet of Things) more devices are connected to the internet, the higher the risk. Securing small, integrated devices is often difficult due to hardware limitations a risk. People share unprecedented amounts of personal information through these services, blindly trusting the platform to safeguard their information. At the same time, people expect the same convenience in their work as they get from the communication platforms they use in their private lives, such as WhatsApp and WeTransfer, that enable them to share information and documents with ease. If this need is not met, people often defer to their preferred applications. As a result, company information can slip from the company's radar, at risk of leaks, reputational damage, and heavy fines under data protection regulations (Al Busaidi, Bhuiyan, \& Zulkifli, 2019; Hussain, Bhuiyan, Said, \& Ab, 2017; Kumarasamy et al., 2021; Rahman \& Bhuiyan, 2019; Shamsi, Ameen, Isaac, Al-Shibami, \& Khalifa, 2018).

The Cloud meet market needs and stay ahead of the competition, with margins shrinking and fickle customer loyalty, companies look to break the value/cost trade-off. Cloud applications or Anything as a Service (XaaS) solutions are attractive options in this transformation, as they offer flexibility and cost reduction at the same time. Substantial expenses on equipment, maintenance, and upkeep can be avoided by using third-party hardware solutions. The security of these third-party services thus becomes essential to the company's own Digital Trust \& Security. Due to the complexity involved in sharing hardware among many different clients, a high level of Digital Trust \& Security knowledge is required to manage a potential breach. Internet of Things. The number of everyday objects that are connected to the internet is increasing exponentially. These connections offer a great many opportunities from package tracking to vehicle maintenance prediction. The number of applications is only matched by the amount of 
Digital Trust \& Security risks that arise with them. IoT devices often connect by hardware of limited capabilities that do not always allow for advanced encryption and security mechanisms. Hackers can take advantage of these weaknesses and potentially take control of, for example, a connected car, with devastating consequences (Patel \& Patel, 2016).

\section{Digital Transformation Adoption in the Public Sector Oman}

The digital transformation cuts across all economic and societal activities, raising opportunities and challenges and calling for adequate policy responses. Job security is the most important determinant of the well-being of the employees. The objectives of this study is to look at the relationship between job security and well-being of workers. Job security and is essential and crucial in order to retain employees in an organization and allow them to work productively and comfortable. The situation of job security is now at the peak level in the workforce. Therefore, based on this scenario it is important for everyone to study the causes and consequences of this economic uncertainty which has resulted to the job insecurity thus affecting the well-being. The issue of job security had existed earlier yet becoming a novel research topic in industrial and organizational psychology. It is well-known that stress and pressure during working is such a normal and common thing in that particular office due to the demands of working style. However, excessive stress and not well-managed may adversely affect the health of workers and an individual's physical and mental well-being. E-Government services implementation level has shown an is fast pace increase in both the developing and the lower-income countries for stimulating good and upright governance capability, accountability and responsibility of public organizations. E-Government services are vital as it helps lift and increase government revenue, very fast and protected transactions, lessen exploitation or bribery through the use of modernized new technology and transparent procedures. It is therefore vital to comment that the e-Service in an e-Governance field has been achieving a more attention over past years. The effective utilization of E-Service technology will no doubt and will help in boosting government revenue, at a very fast pace and with safe transactions (Franke \& Eckhardt, 2014).

\section{METHODOLOGY}

The Sultanate of Oman focusing on technology that enables services and government-wide strategies. Regarding such issues, the main aim of the study is to examine the means available to examine the effectiveness of electronic services and digital transformation in the selected public sector in the Sultanate of Oman. The study used online empirical sources in the names of organizational, technology, environment and human resource factors, as well as the effectiveness of digital change in various online database sources such as Google Scholars, Springer Link, Wiley, Science Direct, JSTOR, Emerald Full text, Scopus and EBSCO HOST, etc. The review findings summarized in this study's for providing the guidance for the future scope of empirical research to ensure the effectiveness of the public sector for digital transformation in the Sultanate of Oman and its regions.

\section{Organizational Factors}

\section{REVIEW FINDINGS}

(Foerster-Metz, Marquardt, Golowko, Kompalla, \& Hell, 2018), The transforming of enterprise dynamic workforce is influenced by the recent digital technology introduced in the market such as; robotics, advanced algorithms and some analytics. Hence, such change in the rising and adoption of these technologies will influence organizational behavior. Organizations future has 
to be prepared with the recent huge developments and it is empirical that companies has to understand the influences and outcomes that will directly be obtained from these factors like recent digitalization, demographic variations and fluctuations, the lack of resources and globalization. Stakeholders are becoming more aware of digitalization due to the recent available technologies. Its influence greatly affects not only the workforce individual characteristics but the enterprise organizational structure as well. Therefore, this becomes a vital contributing factor to organizational behavior as individuals might change how they act and deal within and external side the organization.

(Al-Khouri, 2014), clearly states that there should be a well formulated national strategy for digital identity management is essential to the advance undertaking of existing office economic and social facilities into the digital realm in today's technological world, to the conception of state-of-the-art, innovative and advanced online public and private services and to the digital economy continued development as a whole. Digital identity management accordingly is a vital pillar for the development of the digital economy. Hence, digital identity will enhance the assurance that the new smart identity card for example will deliver the same basis for trust as one would anticipate in a personal transaction of any kind. The findings of (Kamal, Bigdeli, Themistocleous, \& Morabito, 2015), confirms that adopting and evaluating IT can only be effective through the organization's management operation style. The psychological makeup of an individual are largely linked to these factors such as; personality, perception, attitude towards risks and ethics and values and therefore, these will influence and impact the decision making setting and perspective of the organizations' management. The study of (Maroye, van Hooland, Aranguren Celorrio, et al., 2017), points out that no matter how good is the direction of the ongoing projects and activities of the government, still e-government creativities and initiatives of records management doesn't work well. Therefore, archiving guiding principle policy is the basic requirements for a proper records management. Nevertheless, this archiving policy can be affected by reasons of budget, cross-organizational dealings and connections, changes in the organization, some legal uncertainties or doubts in the past and decision making process of the various sectors of public entities.

The study of (Letch \& Teo, 2015), illustrates that the internal and external context of decision and factors related greatly affects the government service transformation. This transformation is not a direct progress of development but rather with a good framework application. To develop a good government service transformation framework a consideration to institutional, political and economic perspective setting is important. On the other hand, (Wee, Phang, \& Khalil, 2018), states that to guarantee and safeguard the state overall well- being, it is imperative that organization management has to be clever and it is essential for government leaders to innovate and create. This can also be boosted thru implementing prestigious awards system achieved by an innovator. (Batalli, 2015) comments that it is a challenging task when services involve catering the whole population of the state. E-services delivery of public administration is challenging and thought-provoking, thus this requires guidelines and procedures in order to determine management practices performances to increase level of efficiency directly or indirectly. (Li et al., 2018), confirms that SMEs under study lacks the needed know how and experience with regards to digital transformation. Entrepreneurs had initiated and determined to adopt digital transformation that upgrading such will increase and improve their capabilities as entrepreneurs. 
(Alrawabdeh, 2014) defines decision making techniques used in e-government is the method of choosing and selecting the best as of between the several alternatives or substitutes. The study also introduced the steps in the decision making that can support the e-government system. Mentioned are the following; interface agents which are responsible for contacting agents on a face to face interaction, information agents are in-charge to collect data or information from agents which are considered as main source of information and are later stored in the proposed system information, consulting agents are in charge of putting all together the alternative plans because they serve as the center for any assessment and choosing and selecting the best design and strategy for the planned system. Lastly the coordination agents are in charge. (Ozols \& Meyerhoff Nielsen, 2018), emphasized that an appropriate coordination and direction between policy, operational, implementation and delivery levels Leadership and control are essential characteristics. It ascertains that it is vital at the beginning and implementation part of government-level transformation and makeover initiatives, such as the entire government methods, other principles and the combined services operations. In order to achieve, a strong leadership so, strong leadership participation is necessary, and at strategic level the decision making is executed and implemented.

(Yusof \& Abdulraheem, 2015). Electronic government or e-government is the computerizing of all data and information. This is in relation of accelerating government system that will help serve the citizens along with the beginning and activation of public policies. Hence, there are two important aspects of e-government to consider; making the citizens as the center and in the participation in e-government decision making and giving the citizens the freedom of expression of their opinions. Transparency can be generated and obtained when there is a collaboration between the citizens and the government through e-decision making, econsultation, and information sharing. As a result, the citizens' participation in e-government rest on the citizens' trust and belief in the government and as well as the culture of the citizens. (Alrawabdeh, 2014), study points out that transparency and citizen participation is greatly influenced by the decision making in the government. There are three basic elements that has connection relating to decision making; corruption and anti-corruption, anti-corruption is evidenced when citizens are given the right to participate in e-government and the cooperation between internet and e-government where people are given the chance to get involve thus trusting the government as a whole.

\section{Technological Factors}

According to (van Dyk \& Van Belle, 2019), the new and well known digital technologies such as social, mobile and etc. could show and present both opportunities and threats in an existing enterprise. Digital technologies are now adopted by leaders, this is to make their products, services and customer relationships even more promising and enterprising because accessibility is at hand. On the other hand, digital technologies empowered business enterprises and other users to connect its features that will help the enterprise to obtain immediate access and interaction of the wide range of data that helps in the making of decision just in time. Similarly, Cloud computing technologies allow and facilitates enterprises to benefit and gain something of value like the reduced costs, flexibility, capacity, utilization and even provide higher efficiencies. However, one biggest barriers found out is the digital strategy which can affect digital transformation and digital maturity that an enterprise adopts. Hence, to achieve the strategic enterprise goals companies must realize the use of digital technologies as a priority in the current technical era. 
(Pesotskaya \& Petrov, 2018), observes that all countries do not adopt an identical plan of procedures, methods and actions with regards to digital transformation. Thus, the state development takes into account the considerations of the availability and capability of innovations. The growth and progress of the digital economy in its electronic ecosystem adoption is greatly influence by the technological compatibility is planned and styled by several factors. (Omar, Weerakkody, \& Sivarajah, 2017) states that to successfully deliver an better-quality service to public organization, the government has to improve its digitally enabled service transformation offers to the society. But in the recent of social technology available, different organizations in their effort to integrate the resources available are somewhat the reasons behind not to embrace the e-services of the government. (Scott, DeLone, \& Golden, 2016), adopted the nine-factor structure to validate Net benefit on public value theory with a comprehension of the impact of Internet-based information system can contribute to the public interest. These factors are the following; Cost, Time, Convenience, Personalization, Communication, Ease of Information Retrieval, Trust, Well-informedness and Participate in Decision-Making. According to (Bilbil, 2017), to be recognized as a smart city, an investment is necessary to factors like; human and social capital which can be categorized as traditional and modern form of communication infrastructure together with a good governance and management of all resources, thus, improving the quality of life through continued economic growth. Further the study states that laws and regulation with regards to ICT infrastructure must have legal basis such as on financial problems, Human Resources, Intra-and Inter institutional coordination.

\section{Environmental Factors}

According to (Maroye, Van Hooland, Celorrio, et al., 2017), the reason for a poor level of implementation are due to some miscellaneous reasons such as the decreasing public budget that makes them incapable to invest in high quality technology, a strongly rooted resistance to change, the tough but inevitable cross-organizational relations between public managements administration, the political doubts arising from a fast-changing digital environment and the political autonomy in the decision-making process of the different public entities affecting the overall implementation and aim of e-services . (Kaya \& Ceylan, 2014), states that organizations have different goals and organizational culture, however, many times employees retain in the organization because of some factors, like when organizational commitment is at its peak, employees working are the ones who adopted the goals and values of the organization thereby, helping the organization at the same time to be successful. (Shagvaliyeva \& Yazdanifard, 2014), Work flexibility implies not only variation in time and place of the job, but also sharing of the job, career breaks (maternity/paternity leaves), part-time and term-time working. In the other study on flexible work arrangement (FWA), researchers discussed three broad categories of FWA-flexi-time (flexibility in scheduling), tele homeworking (flexibility in location), and parttime (flexibility in length of the work) [6]. While each of the arrangement could be used individually, they are frequently combined to complement each other [7]. It should be noted that work flexibility offers convenience in planning, not reducing the working time. (Ahmad, Idris, \& Hashim, 2013). The flexible working hours consists of part time, overtime, long term leaves, job sharing, flexitime and shift work (Chung \& Tijdens, 2013); (Jones \& Jones, 2011). They also stated that the working time referring to the degree of flexibility, gender equity, negotiation structure and diversity of working time. The impact from changes in economy, technology, social and lifestyle in today's environments have boosted the awareness of flexible working arrangements in an organisation. Evidence from the previous study indicated that the competitive 
working environment and increasing workload had caused family and personal life being neglected.

(Rajan, 2018), found out that at Present research found that stress is one of the impact occurred because of heavy workload and this finding is consistent with the study of Rajan D15,16 who in their study found that role related factors which included heavy workload was the reason for stress and it in turn affected individual including health,24 family and social life of sanitary workers. Present research has found that heavy workload is the primary reason for effectuating employees' life negatively in the form of stress and quarrelling with family members and co-workers.25 These findings go with the study of Gidman WK,19 Bond C,20 Eden M,21 Gidman W,22 who observed that workload increased stress levels among pharmacists and disturbed balancing work and family life. According to present research longer working hours is the risk factor associated with heavy workload and this finding is similar with the study of Bond C20 who found that working longer hours because of demand is the reason for heavy workload. Present research has observed that lack of adequate staff and lack of availability of strong job description are reasons for heavy workload and these findings are consistent with the findings of who indicated that pressure from inadequate breaks and a lack of staff were found as causes of workload among pharmacists and with Shann P \& Hassell K25 who investigated that chaotic systems of working, lack of support staff and poor organization.

(Jaworek \& Dyląg, 2015). Opportunities for professional development of women or, at least, meeting growing demands posed by modern work to them, remain limited. On the one hand, women are increasingly visible in public spaces traditionally reserved for men. They participate in the educational process at all available levels. On the other hand, one can still notice disadvantageous differences in pay and the inability to use the bonuses offered by employers in the case of women. The contemporary labour market often requires the oversized commitment and availability of employees. The work also becomes increasingly complex, workload is both of a quantitative and qualitative nature. (Telwatte, Anglim, Wynton, \& Moulding, 2017). Specifically, empathy, legitimacy, necessity, and rated cost all predicted reasonableness ratings, and reasonableness ratings partially explained the effect of these variables on willingness to grant accommodations. Thus, participants appeared to be combining legal reasoning related to perceptions of the legitimacy of the disability and cost-benefit analyses of the accommodation with emotional reasoning related to personal empathy when forming their judgments about what was a reasonable accommodation. However, given that all included disabilities were legitimate and legally protected, if a strictly legal approach were adopted, we would not expect an association between legitimacy and granting. (Balan \& Cavendish, 2017), considers that the description and meaning of management most often have similarities and overlaps leadership concepts theories and models in an organization. The notions and concepts of leadership has been changed from generation to generation, its meaning thoughts and concepts change over time of being much lenient and controlling and therefore nowadays many sees and consider leadership as a major activity of one individual relatively to a role a person has.

On the other hand, (Sow \& Aborbie, 2018), argues that in order for an organization to get its desired output of success results, leadership styles are vital and necessary to consider. In some instances, organizations apply such leadership styles according to their managerial and structural needs, while others do not engage suitable and proper style for their current and prevailing organizations carryout practices. The study of (Al Zefeiti, 2017) points out that transformational leaders encourage, guides human rights through equality along the process of adopting a drive for organizational changes with aspects such as honesty and loyalty, fairness and justice among 
followers. Motivating followers is not only done thru the rational process but rather with the help of transformational leaders that can help increase their emotions towards a satisfied job. (Zeike, Bradbury, Lindert, \& Pfaff, 2019), findings confirm that leadership in digital transformation development in under process of research, whereby they found out that a low psychological wellbeing is a product of upper-level managers with lower digital leadership skills as evidenced under study. (Thuijsman, 2015), came up with a comparison of the following leadership style such as ; transformational leadership, transactional leadership and Laissez Faire leaders. Further he states that, Transformational leadership is a style of leadership whereby the leader recognizes and pinpoints the change required, generates and construct the vision to guide and monitor the change and finally execute the change with the members of the committed group. (Nidadhavolu, 2018), remarks that leading followers or employees to a certain direction depends on the leadership style. Over the years evidenced thru times gone by and history, the quantity of leadership styles has been increasing. Accordingly, the achievement of goal desired by the organization thru its performance can only be effective if the style of leadership adopted is right. Negative output of organizational performance of employees is a product of ineffective leadership style.

\section{Human Resources Factors}

The sharing and applying of collective experience and know-how of employees is derived from knowledge management (KM). The development and implementation of knowledge infrastructure is essential for organizations to be successful. The following are the three dimensions of knowledge infrastructure; a. people, b. organization and c. technological systems. Technological industries innovation strategies is very vital. KM adaptation which involves firm's innovation mostly leads them to success. However, these are dependent on the way it was introduced, how it will be generated, and the combined and exchange of new knowledge plays a great role. Therefore, innovation is the product and sum of new knowledge and the knowledge previously owned by the individual in a specific form. Human resource (HR) is one of the most valuable properties for organizations. The HR is also considered to be the front liner of the organization in time of pandemic as experienced by all the countries in the world. It is the core source of any organization, unlike other resources. HR great role is to improve its performance through its different core competencies. (Dong \& Phuong, 2018).

(Sokhea \& Sophea, 2019), argues on different stand that the barrier of e-government implementation is not only confined on pure technical factor as such ICT infrastructure, privacy and security, but also the organizational issue that plays a great role in the accomplishment of organizations goal. (Sokhea \& Sophea, 2019) advocate the view that Top management support, Resistance to change to electronic ways, Collaboration and Lack of qualified personnel and training are some of the Organizational challenges that needs to be focused. (Al Shobaki, Naser, Amuna, \& El Talla, 2017) It is known that all departments, including human resources management work to achieve success and overcome the problems and crises, through scientific bases that lead to success and the adoption of correct ideas that lead and achieve scientific methods. Thus human resources management is the most important functional departments in the organization because they are dealing with the most important production and more resources of the Organization elements susceptible to changes of the internal environment or external, so organizations began to draw attention to human resources management, it is that department whose main work around the individual worker from the moment of searching for it in the labor market until the moment of the end of its relation to the organization through retirement, 
resignation, dismissal, or stop the services, but some writers go to expand the activity of human resources management, even after the end of the relationship of the individual and the organization that rehabilitated for jobs in other organizations. (Lin \& Lin, 2011), Job satisfaction is a result of a person's interpretation of the feeling, perception, or emotion towards his/her job (Smith, 1969); at the same time, job satisfaction is also an attitude of a person's subjective judgment and feeling towards the level of satisfaction on factors, including benefits and training, communication and care, network resources, and the atmosphere in the organization (Pan, 2005), as well as a person's feeling or emotional reaction toward the role he/she plays in the organization (Vroom, 1964). Job satisfaction is the employees' overall assessment on their jobs. Job satisfaction is the employees' overall assessment on their jobs. In the service industry, job satisfaction ensures that employees receive customers with dignity (Arnett, Laverie, \& McLane, 2002). Since customer reception is significant in terms of establishing customer relations, employees' job satisfaction would be very important to the service industry since businesses in this industry rely heavily on customer loyalty.

According to (Ocen, Francis, \& Angundaru, 2017) adopted from (Armstrong, 2006), job satisfaction is the attitude and feelings or emotional state of people have about their work. In addition, job satisfaction can also be expressed as the feelings or an overall attitude of the employees relative with their jobs like the working environment, working conditions, equitable rewards and communication with the colleagues are some of the major components in consideration. Other definitions are a way of measuring job satisfaction in terms of need fulfillment, discrepancies, value attainment, equity, and dispositional or inherited components model or representations. (Cssmbb, 2016), findings of his study confirmed that there is a significant negative relation between job satisfaction and job withdrawal of employees. Workers who are satisfied with their jobs, do their work with full interest and loyalty and have low chance of withdrawing from their job. In today's changing forms of work and employment where one organization career is becoming rarer and infrequent, employers should keep their employees satisfied and content. Decades in the historical point of view, organizations throughout the GCC states in both public and private sector empower and allow women to achieve a vital and important role in the reach of leadership positions of highly talented women for the first time in many of the senior leadership positions with industry leading companies and government bodies. Leaders of numerous organizations faces challenges and trials along with their responsibilities for effective decision making. Time pressure and uncertainty and insecurity are always at stake together with the crises that leaders may encounter (Alshuaibi, 2017).

\section{Organization Culture}

(Shih \& Koch, 2020) explained that organizations can be differentiated from the culture it embraces. Some can be an advantage to be competitive and others can be powerful to keep the organization on top of the line. No two organizations are the same, they are distinct from each other. An organization that prioritizes culture consistently makes them the big winners. Scholars hold the position and confirm that people in the organization holds different beliefs, behaviors and values, but with the collective effect, Organizational culture plays a vital role in putting all these factors at a collective effect. Therefore, these norms will regulate how the human resources will act as employees to perform their task, cooperate with each other to meet the company's goal, together with the overall mission. Moreover, according to (Shih \& Koch, 2020), culture can be outlined into four types such as; culture is unique, culture gives us a clear guideline, culture are fluid like and growing organic and culture are to become part of their external identity. 
(Kamal et al., 2015), The decision-making process of top management of an organization is influence by an organization culture. The way people do things around the organization is influence by the culture they embrace. Whereas, from an organizational perspective, (Kamal et al., 2015) describes organizational culture as "the combined and shared programming of mind which differentiates the members of one organization from another". Culture can be reflected as risk aversive. Combined responsibility is of some organizations has been observe in decision making, while in others it is a vital responsibility and obligation of individuals (Kaya \& Ceylan, 2014).

\section{Govt. Regulations}

(AlMaimani \& Johari, 2014). Oman in its effort to curtail and lessen the role of oil returns as major profit player in economic development process. The improvement in this regard has been successful in some aspects of the economy and among those is tourism sector. "In a mid-sized, open economy in which the biggest driver of growth so far had been oil, managing the transition to a more diversified economy is challenging. The contributions of other sector in the economy in the year 2015 can be noticed clearly. Such economic sectors would be, the oil sector, which contributed by $34 \%$, followed by the industrial sector by $5 \%$. The non-oil sector has contributed by $61 \%$. All these issues are associated with economic development. The improvement of tourism sector is very important but the authorities also should take the negative that results from such activities seriously. It is clear that the government has put strict measures to protect the environment and its nature including flora and fauna (AlMaimani \& Johari, 2014).

\section{Digital Transformation in the Public Sector}

The digital transformation cuts across all economic and societal activities, raising opportunities and challenges and calling for adequate policy responses. Job security is the most important determinant of the well-being of the employees. E-services constitute a new model for using the Web. It allows the publishing of business functions to the Web and enables universal access to these functions. The architecture that enables it, is presented in the following paragraphs along with the benefits that this architecture could bring to e-business. (Siddiquee, 2016), comments that E-government and services must be seen and taken into account as a long-term project, that can draw attraction and fascinate high level of political support and backing leading to a productive and rewarding partnership and teamwork between the public, private and nongovernmental actors in general. Therefore, based on this scenario it is important for everyone to study the causes and consequences of this economic uncertainty which has resulted to the job insecurity thus affecting the well-being. The issue of job security had existed earlier yet becoming a novel research topic in industrial and organizational psychology. It is well-known that stress and pressure during working is such a normal and common thing in that particular office due to the demands of working style. However, excessive stress and not well-managed may adversely affect the health of workers and an individual's physical and mental well-being. E-Government services implementation level has shown an is fast pace increase in both the developing and the lower-income countries for stimulating good and upright governance capability, accountability and responsibility of public organizations. E-Government services are vital as it helps lift and increase government revenue, very fast and protected transactions, lessen exploitation or bribery through the use of modernized new technology and transparent procedures. It is therefore vital to comment that the e-Service in an e-Governance field has been achieving a more attention over past years. The effective utilization of E-Service technology will 
no doubt and will help in boosting government revenue, at a very fast pace and with safe transactions (Kurfal1, Arifoğlu, Tokdemir, \& Paçin, 2017).

Moreover, it is time to shift to the e-government method leaving the old-fashioned or traditional one. Although e-government practices have been assumed and embraced within the public administration, it is essential therefore to ensure the state understanding with regards to the provision of e-services to its citizens. Somehow e-government has a positive effect in its public performance (Benzer, 2015). ICT in government operations on the other hand is vital in the provision of information services. According to (Al-Khouri, 2014), digital identity in terms of management is a vital support for the improvement of the digital economy. Digital identity will form confidence of users and gaining trust in any undertaking regarding personal transactions. The innovative creation of online services to the continued development of the digital economy has impact opportunities of innovation in terms of e-service delivery to citizens of the state (Bataineh \& Al Mutawa, 2016).

(Oseni \& Dingley, 2015) elaborated that the history of computing as a tool used by government establishments emerged in the late 1990's where the computer itself can be traced back like any other e-platform concepts such as the concept of e-commerce, and lately the birth of e-government from the internet world. (Naqvi \& Al-Shihi, 2014), states that the Sultanate of Oman has reserved its position of being the $40^{\text {th }}$ in position in the world with regards to technological readiness, which is evidenced in countries with strong and competitive vision in the development of their Information and Communications Technology capacity ( ICT ) having dominant economic presence. There are however, many E-Services recently are available today at all stages both in private and government institutions and in most industrialized and developing countries. In their study (Oseni \& Dingley, 2015), mentioned and confirm the various types of E-Services of which the following are; E-payment, E-assessment, E-complaint, Elicensing, E-compound, E-submission, E-rental, E-forum, E-Learning and E-tax (Oseni \& Dingley, 2015).

\section{CONCLUSION AND RECOMMENDATIONS}

As the study aims to develop a conceptual framework between the e- service, digital transformations attributes and efficiency of the digital transformation, Oman. In order to development of conceptual model study examined review of literature on about the effectiveness of electronic services and digital transformation in the selected public sector in the Sultanate of Oman. The investigation showed that introduction of flexible working hours brought some benefits for both employee and employer. The results from this research confirmed that the implementation of flexible working hour schedule contributed to the staff motivation and allows staff to perform duties in a comfortable, peaceful and less stress condition that can elevate staff motivation level, meet present and future challenges by creating choice, accommodating generations, enabling complexity, and creating agility. The study also found that the productivity and employee turnover are the most commonly debated terms in all kinds of sectors in this current business world as they are directly associated with growth of both employees and organization. Despite many factors, workload which is the amount of work assigned to or expected from a worker in a specified time period remain one of the principal factor deciding both productivity and turnover of the employees. In summary, it is argued that application of the HF psychology workload concept to the measurement of job stressors would support such developments. 
Study results provide an understanding of the relationships between demographics, knowledge, attitudes, experience, and accommodation decision-making in a sample of managers and HR professionals. In order to ascertain such proposal and application for a significant successful operations leaders and other resources collaboration is needed in the application and adoption of digital transformation operation. The study found that the leadership styles that managers adopted greatly influenced employee change perception and awareness. Change or transformation is vital to implement thereby avoiding conflict that are currently existing amongst employees. Job rotation programmed enables a worker to make a career in a workplace and stand the chance of climbing the leadership ladder to the top. That is, gaining promotion from one level to another based on his competency, efficiency, productivity, and effectiveness in the performance of a given task. Moreover, the training methods are meant to motivate, enlighten, update, acquaint and educate workers on what to do thereby ensuring efficiency in the operation of an organization. Job rotation is an aspect of training undergone in an organization involving both managers and non-managers. It occurs when an employee is moved from one job, department, or task to another after spending sometime in a particular job, task, assignment, or department with a view of enabling the employees to acquire more skills, talents and knowledge. In a way, job rotation is influenced by coordination and is meant to broaden one's outlook, knowledge, skill, and contact.

The study concluded that the culture is being distinctive because there is no single factor that can answer to this. There can be different answers even if organizations have the same goal to attain that is to keep their employees happy. On the other hand, culture provides and contribute us with a clear guideline

Results of this research show that the digital transformation is profoundly affecting the ways in which people contribute to societies, live and work, including in terms of the number and types of jobs available. The impact of digitalization on the workforce depends on technological innovations and uptake of these new technologies. The digital transformation is changing the labour market Digitalization creates jobs both directly, for example new jobs like data analysts, social media marketers or Internet of Things architects, and indirectly by raising productivity, lowering prices and thereby stimulating demand.

Finally, the review results show that organizational, technological, environmental and human factors play an important role in ensuring the effectiveness of the public sector in the digital transformation in the Sultanate of Oman. The study also found that the success of egovernment in Oman depends on the willingness and intention of citizens to use e-government services. The country's government should consider developing vital IT projects, ignoring citizens' opinions, to make traditional services more efficient online. Understanding citizen adoption is an important element of E-Government, enabling it to provide policymakers and decision makers with a range of strategic management plans and actions to build and rapidly accelerate adoption of these services to increase citizen participation also the adoption rate. A summary of the study's findings provides guidance for the future scope of empirical research to ensure the effectiveness of the public sector for digital transformation in the Sultanate of Oman and its regions.

\section{REFERENCES}

Ahmad, A. R., Idris, M. T. M., \& Hashim, M. H. (2013). A study of flexible working hours and motivation. Asian Social Science, 9(3), 208-215. 
Al-Busaidy, M., \& Weerakkody, V. (2011). E-government services in Oman: an employee's perspective. Electronic Government, An International Journal, 8(2-3), 185-207.

Al-Khouri, A. M. (2014). Digital identity: Transforming GCC economies. Innovation, 16(2), 184-194.

Al Busaidi, N. S., Bhuiyan, A. B., \& Zulkifli, N. (2019). The Critical Review on the Adoption of ICTs in the Small and Medium Enterprises (SMEs) in the Developing Countries. International Journal of Small and Medium Enterprises, 2(2), 33-40.

Al Salmi, M., Mohtar, S., \& Hasnan, N. (2017). How to implement successful e-Government: Case study of Sultanate of Oman.

Al Shobaki, M. M., Naser, S. S. A., Amuna, Y. M. A., \& El Talla, S. A. (2017). The Efficiency of Information Technology and its Role of e-HRM in the Palestinian Universities. International Journal of Engineering and Information Systems, 1(5), 36-55.

Al Zefeiti, S. M. B. (2017). The Influence of Transformational Leadership Behaviours on Oman Public Employees' Work Performance. Asian Social Science, 13(3), 102-116.

AlMaimani, J., \& Johari, F. B. (2014). Tourism development plan in Oman. Indicator, 2015, $2016 p$.

Alrawabdeh, W. (2014). The Impact of environmental factors on e-government implementation: The case of Jordan. International Journal of Management Sciences and Business Research, 3(3).

Alshuaibi, A. (2017). Technology as an important role in the implementation of Saudi Arabia's vision 2030. International Journal of Business, Humanities and Technology, 7(2), 52-62.

Armstrong, M. (2006). Performance management: Key strategies and practical guidelines: Kogan Page Limited.

Arnett, D. B., Laverie, D. A., \& McLane, C. (2002). Using job satisfaction and pride as internalmarketing tools. Cornell hotel and restaurant administration quarterly, 43(2), 87-96.

Balan, A. C., \& Cavendish, K. (2017). Leadership in the Digital and Social Era-A Theoretical Review and Digital Gamification for Employee Development.

Bataineh, E., \& Al Mutawa, S. (2016). An Analysis Study of Factors That Determine E-Services Usage by End Users: A Case Study. Journal of e-Government Studies and Best Practices, 2016, 1-15.

Batalli, M. (2015). Measurement and e valuation of the public administration performance through delivery of electronic services. Academicus International Scientific Journal, 6(12), 169-179. 
Benzer, R. (2015). E-Government in Developed Countries, The Case of Turkey. IJCSIT) International Journal of Computer Science and Information Technologies, 6(1), 710714.

Bilbil, E. T. (2017). The operationalizing aspects of smart cities: The case of Turkey's smart strategies. Journal of the Knowledge Economy, 8(3), 1032-1048.

Chung, H., \& Tijdens, K. (2013). Working time flexibility components and working time regimes in Europe: using company-level data across 21 countries. The International Journal of Human Resource Management, 24(7), 1418-1434.

Cssmbb, M. (2016). What is job-satisfaction? Explain the effects of job-satisfaction on job withdrawal of employees.

Cummings, T. G., \& Feyerherm, A. E. (2016). Transformation and Change in Large Systems. Practicing Organization Development.

Dong, L. N. T., \& Phuong, N. N. D. (2018). Organizational justice, job satisfaction and organizational citizenship behavior in higher education institutions: A research proposition in Vietnam. The Journal of Asian Finance, Economics, and Business, 5(3), 113-119.

Filgueiras, F., Flávio, C., \& Palotti, P. (2019). Digital Transformation and Public Service Delivery in Brazil. Latin American Policy, 10(2), 195-219.

Foerster-Metz, U. S., Marquardt, K., Golowko, N., Kompalla, A., \& Hell, C. (2018). Digital transformation and its implications on organizational behavior. Journal of EU Research in Business, 2018(S 3).

Franke, R., \& Eckhardt, A. (2014). Crucial factors for E government implementation success and failure: case study evidence from Saudi Arabia.

Hussain, M. D., Bhuiyan, A. B., Said, J., \& Ab, M. S. B. (2017). Entrepreneurship Education is the Key Contrivance of Poverty Alleviation: An Empirical Review. MAYFEB Journal of Business and Management, 1.

Jaworek, M., \& Dyląg, A. (2015). Perception of work environment among women and men: workload and autonomy in relation to job engagement. Jagiellonian Journal of Management, 1(3).

Jones, K., \& Jones, E. (2011). Flexible working practices in the UK: Gender and management perspectives. Journal of women in society, 2, 1-8.

Kamal, M. M., Bigdeli, A. Z., Themistocleous, M., \& Morabito, V. (2015). Investigating factors influencing local government decision makers while adopting integration technologies 
(IntTech). Information \& Management, $\quad$ 52(2), $\quad$ 135-150. doi:https://doi.org/10.1016/j.im.2014.06.007

Kaya, C., \& Ceylan, B. (2014). An empirical study on the role of career development programs in organizations and organizational commitment on job satisfaction of employees. American Journal of Business and Management, 3(3), 178-191.

Kumarasamy, M. M., Hasbolah, F., Hamzah, H., Mohd Fazmi, K. N., Omar, S. A., \& Bhuiyan, A. B. (2021). Conceptual review between religiosity, work-life balance and employee performance of the employees in Higher Education Institutions (HEIs).

Kurfalı, M., Arifoğlu, A., Tokdemir, G., \& Paçin, Y. (2017). Adoption of e-government services in Turkey. Computers in Human Behavior, 66, 168-178.

Letch, N., \& Teo, J. (2015). Accounting for the contexts of government service transformation. Transforming Government: People, Process and Policy, 9(3), 352-369. doi:10.1108/TG08-2014-0035

Li, L., Su, F., Zhang, W., \& Mao, J. Y. (2018). Digital transformation by SME entrepreneurs: A capability perspective. Information Systems Journal, 28(6), 1129-1157.

Lin, S.-C., \& Lin, J. S.-J. (2011). Impacts of coworkers relationships on organizational commitment-and intervening effects of job satisfaction. African Journal of Business Management, 5(8), 3396-3409.

Marchio, G., Benedetti, M., \& Russo, C. (2015). How to Spread e-Government? A Two-Step Framework to Define Innovation Strategies. Paper presented at the Proceedings of The 15th European Conference on eGovernment ECEG 2015 University of Portsmouth.

Maroye, L., van Hooland, S., Aranguren Celorrio, F., Soyez, S., Losdyck, B., Vanreck, O., \& de Terwangne, C. (2017). Managing electronic records across organizational boundaries. Records management journal, 27(1), 69-83. doi:10.1108/RMJ-11-2015-0037

Maroye, L., Van Hooland, S., Celorrio, F. A., Soyez, S., Losdyck, B., Vanreck, O., \& de Terwangne, C. (2017). Managing electronic records across organizational boundaries. Records management journal.

Naqvi, S. J., \& Al-Shihi, H. (2014). Factors Affecting M-commerce Adoption in Oman using Technology Acceptance Modeling Approach. TEM Journal, 3(4), 315.

Nidadhavolu, A. (2018). Impact of leadership styles on employee job satisfaction and organizational commitment-A study in the construction sector in India.

Ocen, E., Francis, K., \& Angundaru, G. (2017). The role of training in building employee commitment: the mediating effect of job satisfaction. European Journal of Training and Development. 
Omar, A., Weerakkody, V., \& Sivarajah, U. (2017). Digitally enabled service transformation in UK public sector: A case analysis of universal credit. International Journal of Information Management, 37(4), 350-356.

Oseni, K. O., \& Dingley, K. (2015). Roles of E-Service in Economic Development, Case Study of Nigeria, a Lower-Middle Income Country. International Journal of Managing Information Technology (IJMIT), 7.

Ozols, G., \& Meyerhoff Nielsen, M. (2018). Connected Government Approach for Customercentric Public Service Delivery: Comparing strategic, governance and technological aspects in Latvia, Denmark and the United Kingdom.

Pan, W. (2005). A study on the personal background, motivation, and job satisfaction of museum volunteers-A case study of Kaohsiung Museum of History. master thesis, Graduate Institute of Education Administration, National ...,

Patel, K. K., \& Patel, S. M. (2016). Internet of things-IOT: definition, characteristics, architecture, enabling technologies, application \& future challenges. International journal of engineering science and computing, 6(5).

Pesotskaya, E., \& Petrov, I. (2018). International experience of state support and encouragement of digital economy processes. Paper presented at the SHS Web of Conferences.

Rahman, M. Z., \& Bhuiyan, A. B. (2019). The Influencing Factors on the Effectiveness of Foundation Training Programs: A Case Study of the Health Cadre Service in Bangladesh. International Journal of Business and Management Future, 3(2), 13-21.

Rajan, D. (2018). Negative impacts of heavy workload: A comparative study among sanitary workers. Sociol. Int. J, 2(6), 465-474.

Rossouw, J., \& Alexander, P. (2015). A practical transition of employees towards information systems adoption: A public service perspective.

Scott, M., DeLone, W., \& Golden, W. (2016). Measuring eGovernment success: a public value approach. European Journal of Information Systems, 25(3), 187-208.

Shagvaliyeva, S., \& Yazdanifard, R. (2014). Impact of flexible working hours on work-life balance. American Journal of Industrial and Business Management, 2014.

Shamsi, R. S. H. A., Ameen, A. A., Isaac, O., Al-Shibami, A. H., \& Khalifa, G. S. (2018). The impact of innovation and smart government on happiness: Proposing conceptual framework. International Journal of Management and Human Science (IJMHS), 2(2), 10-26.

Shih, Y. W., \& Koch, A. (2020). Psychological Safety for Organizational Cultural Change: An exploratory study in a Swedish multinational chemical engineering company. In. 
Siddiquee, N. A. (2016). E-government and transformation of service delivery in developing countries. Transforming Government: People, Process and Policy.

Smith, P. C. (1969). The measurement of satisfaction in work and retirement: A strategy for the study of attitudes.

Sokhea, S., \& Sophea, S. (2019). The Influence of Organization Factor on E-service Adoption: The Case of Cambodia.

Sow, M., \& Aborbie, S. (2018). Impact of leadership on digital transformation. Business and Economic Research, 8(3), 139-148.

Telwatte, A., Anglim, J., Wynton, S. K., \& Moulding, R. (2017). Workplace accommodations for employees with disabilities: A multilevel model of employer decision-making. Rehabilitation psychology, 62(1), 7.

Thuijsman, T. (2015). Leadership styles and their influence on employees regarding the acceptance of organizational change. University of Twente,

van Dyk, R., \& Van Belle, J.-P. (2019). Factors influencing the intended adoption of digital transformation: a South African case study. Paper presented at the 2019 Federated Conference on Computer Science and Information Systems (FedCSIS).

Vroom, V. H. (1964). Work and motivation.

Wee, J. S., Phang, S. N., \& Khalil, S. (2018). Re-thinking government administration: Issues of decentralization, Public service innovation and transformation in Malaysia. International Journal of Management Research \& Review, 3(2), 7-16.

Yusof, S. A. B. M., \& Abdulraheem, M. H. (2015). Real Factors which Impact on Decision Making in the E-government. Paper presented at the 2015 6th International Conference on Intelligent Systems, Modelling and Simulation.

Zeike, S., Bradbury, K., Lindert, L., \& Pfaff, H. (2019). Digital leadership skills and associations with psychological well-being. International journal of environmental research and public health, 16(14), 2628.

\section{Copyrights}

Copyright for this article is retained by the author(s), with first publication rights granted to the journal. This is an open-access article distributed under the terms and conditions of the Creative Commons Attribution license (https://creativecommons.org/licenses/by/4.0) 